\title{
Implikatur Percakapan Pragmatis dalam Novel Pelukan yang Dingin Karya V. Lestari
}

\author{
Sholihul Amri* \\ Program Studi Teknik Sipil Fakultas Teknik Universitas Islam Lamongan \\ amrisholihul@unisla.ac.id
}

Pengiriman: 29/09/2020; Diterima: 23/10/2020; Publikasi: 23/11/2020

DOI: $10.31629 /$ jermal.v1i2.2548

\begin{abstract}
Abstrak
Penelitian ini bertujuan untuk mendeskripsikan implikatur percakapan pragmatis dalam Novel Pelukan yang Dingin serta pelanggaran dan kepatuhan terhadap prinsip kerja sama (teori Grice). Penelitian ini menggunakan metode penelitian deskriptif. Teknik pengumpulan data yaitu teknik simak dan teknik catat dan langkah-langkah pengolahan data sebagai berikut: teknik identifikasi, teknik klasifikasi, teknik analisis, dan teknik pembahasan analisis data. Instrumen penelitian ini menggunakan kartu data. Sampel yang diambil peneliti adalah 490 halaman dari sampel tersebut dapat ditemukan 77 percakapan yang termasuk implikatur. Jadi dari data yang ditemukan tersebut dianalisis berdasarkan maksud atau makna yang tersirat dalam percakapan, serta konteks yang melatari sebuah percakapan tersebut. Percakapan yang terdapat dalam novel ini masih termasuk patuh atau menggunakan prinsip kerja sama dengan lebih tepat karena setelah dianalisis dan persentase angka menunjukkan $59.7 \%$ ke atas, sedangkan yang melanggar atau tidak menggunakan prinsip kerja sama adalah $40.2 \%$ ke bawah.

Kata Kunci: implikatur percakapan, pragmatik, prinsip kerja sama.
\end{abstract}

\section{Abstract}

This study aims to describe the implications of pragmatic conversations in Cold Hugs Novels and violations and adherence to the principle of cooperation (Grice's theory). This research uses descriptive research method. With data collection techniques, namely observation techniques and note-taking techniques and data processing steps as follows: identification techniques, classification techniques, analysis techniques, and data analysis discussion techniques. This research instrument using a data card. The sample taken by the researcher was 490 pages. From the sample, 77 conversations were found including implicatures. So the data found were analyzed based on the intent or meaning implied in the conversation, as well as the context behind a conversation. The conversations contained in this novel are still obedient or use the principle of cooperation more precisely because after being analyzed and the percentage of numbers shows $59.7 \%$ and above, while those who violate or do not use the principle of cooperation are $40.2 \%$ and below.

Keywords: Conversational implicature, praxmatics, cooperation principle.

\section{PENDAHULUAN}

Bahasa merupakan kunci utama dalam berkomunikasi. Tanpa bahasa manusia akan sulit berkomunikasi dengan sesamanya. Jadi, manusia tidak terlepas dari bahasa karena bahasa sebagai sarana komunikasi yang sangat vital. Salah satu perwujudan bentuk komunikasi adalah percakapan.
Di dalam percakapan kita sering mengalami ketidakpahaman dalam mememahami ujaran kalimat penutur atau lawan bicara kita, sehingga kita mengalami kesalahan dalam menanggapi kalimat yang diujarkan oleh penutur. Maka dari itu, dalam setiap kegiatan percakapan penutur 
dan pendengar harus memerhatikan struktur kalimat dan tanda baca. Semua itu bisa disebut juga dengan pragmatik, yaitu ilmu yang berkenaan dengan syarat-syarat yang mengakibatkan serasi tidaknya pemakaian bahasa dalam komunikasi.

Dalam kegiatan sehari-hari, kita sering melihat dan mengamati orang-orang sekeliling kita, berkomunikasi tidak menggunakan struktur kalimat dan tanda baca yang semestinya, sehingga timbulah implikasi yang kadang menjadikan pendengar salah menafsirkan kalimat yang disampaikan oleh penutur. Menurut Wijana dan Rohmadi (2011:120) implikatur merupakan salah satu aspek kajian yang penting atau mungkin yang paling penting dalam studi kebahasaan yang berbau pragmatik. Selanjutnya, menurut Chaer (2010: 33) implikatur atau implikatur percakapan adalah adanya keterkaitan antara ujaran dari seseorang penutur dan lawan tuturnya. Namun, keterkaitan itu tidak tampak secara literal; tetapi dipahami tersirat.

Lebih lanjut menurut Rahardi (2005: 42-43), bahwa di dalam pertuturan yang sesungguhnya, penutur dan mitra tutur dapat secara lancar berkomunikasi karena mereka berdua memiliki semacam kesamaan latar belakang pengetahuan tentang sesuatu yang dipertuturkan itu. Di antara penutur dan mitra tutur terdapat semacam kontrak percakapan tidak tertulis bahwa apa yang sedang dipertuturkan itu saling dimengerti.

Implikatur percakapan yang diujarkan langsung oleh penutur dan lawan tutur dalam kehidupan sehari-hari disebut percakapan lisan. Akan tetapi, percakapan tidak hanya lisan seperti di atas, melainkan ada juga jenis percakapan tulis, seperti yang terdapat dalam novel, surat kabar, naskah drama, dan lain sebagainya. Penelitian ini membahas implikatur percakapan tulis yang terdapat dalam sebuah novel.

Seperti halnya percakapan lisan, percakapan dalam novel juga terdiri atas beberapa partisipan, yaitu penutur dan lawan tutur, yang diwujudkan dengan tuturan-tuturan. Percakapan tersebut berupa kalimat yang kadang bersifat implisit dalam menyampaikan maksud atau pesan dari para tokohnya. Hal itu sering menjadikan pembaca mengalami kesulitan dalam menafsirkan, sehingga maksud atau pesan yang ingin disampaikan dalam novel itu tidak bisa diterima oleh pembaca dengan pasti. Agar dapat memahami percakapan implisit dalam sebuah novel, pembaca harus memahami pula konteks yang melatarinya. Konteks yang dimaksud adalah kapan dan di mana terjadinya percakapan, pembicaraan antara siapa dengan siapa, memiliki hubungan apa penutur dan lawan tutur dan suasananya bagaimana.

Penelitian ini meneliti kepatuhan menggunakan prinsip kerja sama dalam novel, setiap penutur wajib melaksanakan 4 maksim percakapan, yaitu maksim kuantitas, maksim kualitas, dan maksim relevansi, dan maksim implementasi”.

Grice (dalam Sumarsono, 2010:116117) memberikan contoh persoalan berikut. Si A bertanya kepada B tentang teman mereka, C, yang bekerja di sebuah bank, dan jawaban B ialah:

(10) oh, quite well, I think; he likes his colleagues, and hasn't been to prision yet, (oh, saya kira lumayan; dia menyenangi rekan-rekan kerjanya, dan belum pernah dipenjara).

Jawaban B itu bisa mendorong A untuk menanyakan lebih lanjut apa yang dimaksud oleh B dengan "belum pernah dipenjara" itu. Jika ini terjadi, maka B dapat menjawab dengan mengatakan bahwa $\mathrm{C}$ itu orang yang gampang tergoda oleh kesempatan (menggelapkan uang) yang ada di tempat kerjanya itu; atau bahwa rekan-rekan kerjanya di bank itu adalah orang-orang jahat (suka menjerumuskan orang-orang baru kerja di bank); atau jawaban senada, tetapi boleh jadi A tidak bertanya seperti itu, karena, berdasarkan konteks pembicaraan mereka, 
A sudah memahami apa yang dimaksud oleh B dengan "belum pernah dipenjara" tadi. Yang tampaknya cukup jelas bagi kita ialah bahwa apa yang dimaksud oleh B jelas berbeda apa yang diujarkan, yaitu "belum pernah dipenjara". Maksud yang ada di balik ujaran itulah yang disebut implikatum oleh Grice. Kata implikatum bermakna 'apa yang diimplikasikan; apa yang dikandung', dan gejala ini disebut implikatur (implicature).

\section{METODE PENELITIAN \\ Jenis Penelitian}

Metode yang digunakan dalam penelitian ini menggunakan metode deskriptif. Menurut Sudaryanto (1992:62), Metode deskriptif adalah metode penelitian yang hanya didasarkan pada fakta atau fenomena yang dialami secara empiris penuturpenuturnya. sehingga yang dihasilkan berupa perian bahasa seperti apa adanya.

Karakteristik penelitian ini menggunakan metode deskriptif, yaitu dalam penelitiannya tidak mempertimbangkan benar salahnya penggunaan bahasa oleh penuturnya. Tujuan yang dicapai dalam penelitian ini adalah mendeskripsikan implikatur percakapan dan prinsip kerja sama dalam implikatur percakapan pada novel Pelukan Yang Dingin karya V.Lestari. Metode deskriptif ini dilakukan melalui pengumpulan data yang disusun, dianalisis, diklasifikasikan, ditafsirkan atau dibahas dan disimpulkan.

\section{Subjek dan Objek Penelitian}

Subjek dalam penelitian ini adalah Novel Pelukan yang Dingin karya V. Lestari. Objek penelitian yang dianalisis adalah percakapan implikatur yang ada dalam novel Pelukan yang Dingin karya V. Lestari.

\section{Teknik Pengumpulan Data}

Teknik pengumpulan data dalam penelitian ini adalah teknik catat. Teknik catat dilakukan dengan pencatatan pada kartu data yang dilanjutkan dengan klasifikasi atau pengelompokan. Data yang dikumpulkan kemudian dicatat dalam kartu data, pencatatan dapat dilakukan langsung ketika teknik pertama selesai dan dengan menggukan media alat tulis tertentu yaitu laptop (Sudaryanto 1993: 135).

\section{Teknik Catat}

Setelah teknik simak berhasil dilakukan, teknik selanjutnya adalah catat. Teknik catat dilakukan untuk mencatat penggalan percakapan dalam novel Pelukan yang Dingin yang termasuk implikatur percakapan. Selanjutnya percakapan dicatat pada kartu data.

\section{Langkah-langkah Pengolahan Data}

Dalam mengolah data, peneliti menggunakan analisis pragmatik. Analisis ini berupaya untuk menemukan maksud penutur baik yang diekspresikan secara tersurat maupun yang digunakan secara tersirat dibalik tuturan. Yang dimaksud adalah implikatur percakapan dalam novel Pelukan yang Dingin.

\section{Teknik Identifikasi}

Teknik analisis data yang digunakan dalam penelitian ini adalah teknik identifikasi. Teknik identifikasi adalah teknik yang dilakukan dengan cara menetapkan data yang termasuk implikatur percakapan kemudian mengidentifkasi data (percakapan) yang termasuk jenis implikatur percakapan dan prinsip kerja sama berdasarkan karakteristik masingmasing objek yang dikaji.

Setelah data berbentuk transkripsi dan terkumpul, kemudian pada tahap ini penulis mengidentifikasi objek yang akan diteliti dengan cara menandai kata, kelompok kata atau kalimat yang mengandung implikatur percakapan dan prinsip kerjasama dalam novel Pelukan yang Dingin.

\section{Teknik Klasifikasi}

Proses klasifikasi dilakukan dengan cara mengelompokkan data berdasarkan implikatur percakapan dan prinsip kerja sama dalam novel Pelukan yang Dingin.

\section{Teknik Analisis}

Setelah data diidentifikasi dan diklasifikasikan, langkah selanjutnya yaitu 
melakukan analisis berdasarkan implikatur percakapan dan prinsip kerja sama yang terdapat dalam novel Pelukan yang Dingin. Analisis ini diawali dengan pencatatan identitas pada kartu data yang kemudian dilakukan analisis data yang berupa pendeskripsian atau penafsiran terhadap data. Setelah semua data dianalisis kemudian data disimpulkan berdasarkan analisis.

\section{Teknik Pengolahan Data}

Kegiatan pengolahan data ini merupakan tahap penelitian yang dilakukan setelah pengumpulan data. Pengolahan data dilakukan sesuai dengan pokok persoalan yang diteliti, yaitu implikatur percakapan pada novel Pelukan yang Dingin. Pengolahan data ini akan mempermudah tahap selanjutnya yaitu tahap mengklasifikasikan data dan menganalisis data. Data yang telah terkumpul, kemudian dipilih mana yang ada implikatur dan mana yang tidak ada.

\section{Sumber Data Penelitian}

Sumber data penelitian ini diambil dari percakapan yang terdapat dalam novel V.Lestari yang berjudul Pelukan Yang Dingin. Sumber data yang digunakan dalam penilitian dapat berupa manusia, peristiwa dan tingkah laku, dokumen atau arsip-arsip benda-benda lain. Sumber data dalam penelitian ini sebagai berikut.

1. Sumber data primer adalah sumber asli, sumber pertama peneliti. Dari sumber data primer ini akan dihasilkan data primer, yaitu data yang langsung dan segera diperoleh dari sumber data oleh peneliti untuk tujuan khusus. Sumber data primer dari penelitian ini adalah kalimat percakapan novel Pelukan yang Dingin yang telah ditranskripsi.

2.Sumber data sekunder adalah sumber data yang berkedudukan sebagai penunjang penelitian. Sumber data sekunder dalam penelitian ini diperoleh dari buku yang relevan dengan teori yang yang menunjang penelitian yang akan dilakukan ini.

\section{Korpus Penelitian}

Data yang digunakan dalam penelitian ini yaitu berupa tuturan. Tuturan yang dimaksud adalah percakapan yang mengandung implikatur percakapan yang berupa implikasi pragmatis impikatur percakapan dan prinsip kerja sama pada percakapan yang terkandung dalam novel Pelukan yang Dingin.

Korpus data diambil dalam pada tahun 2010. Adapun data yang akan diteliti yaitu percakapan novel Pelukan yang Dingin karya V.Lestari yang di terbitkan oleh PT Gramedia Pustaka Umum pada bulan April tahun 2010, dengan nomor ISBN: 978-979-22-5216-3.

\section{HASIL PENELITIAN DAN PEMBAHASAN}

\section{Hasil Penelitian}

Pada bagian ini akan dipaparkan hasil temuan dan pembahasan tentang implikatur percakapan dalam novel Pelukan yang Dingin karya V. Lestari. Temuan yang peneliti temukan di sini adalah data yang hanya berupa sampelnya saja, sampel yang diambil peneliti adalah 490 halaman dari sampel tersebut dapat ditemukan 77 percakapan yang termasuk implikatur. Jadi dari data yang ditemukan tersebut akan dianalisis berdasarkan maksud atau pesan yang tersirat dalam percakapan, serta konteks yang melatari sebuah percakapan tersebut. Konteks yang dimaksud di sini adalah kapan atau di mana terjadinya percakapan, memiliki hubungan apa antara penutur dan lawan tutur dan suasananya bagaimana. Berikut ini hasil dari analisis implikatur percakapan pragmatis.

Singgih : "Apa? Bicara..."
Kelana
kasihan?"(16)

$>$ Konteks : Pembicaraan antara Singgih dan Kelana, mereka adalah satu rekan kerja dan Singgih adalah atasan Kelana. Percakapan terjadi di ruangan Singgih, suasana pada saat itu sedikit tegang. 
Maksud dari percakapan tersebut adalah Singgih merasa ngeri dan takut, karena sebelumya Kelana meminta izin cuti dengan menyebut arwah Omnya yang sudah meninggal dunia, daripada berurusan dengan arwah akhirnya Singgih memberi Kelana izin cuti satu minggu untuk mengurus warisan.

Amelia : "Waduh, aku repot donk. Pekerjaanku seabrek."

Kelana : "Ah, kita kan sudah santai sekarang. Segalanya sudah diurus mesin ATM,"'(17)

Konteks : pembicaraan antara Amelia dan Kelana, mereka adalah pasangan kekasih yang bekerja di kantor yang sama. Percakapan terjadi di ruang kerja mereka, suasana pada saat itu sedikit tegang.

$>$ Maksud dari percakapan tersebut adalah, Amelia sebenarnya tidak setuju kalau Kelana diizinkan cuti selama satu minggu. Dia bisa kerepotan karena menganggap pekerjaan di kantor lagi banyak. Akan tetapi, semua pekerjaan di kantor tidak serepot yang dibayangkan Amelia, karena semuanya dikerjakan dengan menggunakan mesin ATM.

Kelana : "Aku nggak suka baca koran"

Nora : "Nggak ada teman yang memberitahumu?"(22)

Konteks : Pembicaraan antara Kelana dan Nora. Nora adalah notaris yang mengurusi harta warisan yang ditinggalkan oleh Om Jo (Om Kelana. Percakapan terjadi di kantor Nora, suasana pada saat itu santai.

Maksud dari percakapan tersebut adalah, Kelana tidak suka membaca koran dan tidak mempunyai teman banyak, padahal dulu Nora sempat memasang iklan tentang kehilangan orang di koran dan berharap keberadaan Kelana dapat diketahui karena Kelana dulu tiba-tiba pergi meninggalkan rumah tanpa memberi kabar kepada Om jo.
Kelana : "Oh, mobilnya"

Nora : "Ya. Chevrolet pick-up warna hitam"

Kelana : "Masih yang dulu"(26)

Konteks : Pembicaraan antara Kelana dan Nora, Nora adalah notaris yang mengurusi harta warisan yang ditinggalkan oleh Om Jo (Om Kelana). Percakapan terjadi di tempat pemakaman kuburan Om Jo, suasana pada saat itu santai.

> Maksud dari percakapan tersebut adalah, Om Jo juga meninggalkan sebuah mobil kepada Kelana yaitu mobil Chevrolet pick-up warna hitam, kata Nora. Mobil tersebut sudah diketahui oleh Kelana, karena dulu saat masih tinggal bersama Om Jo Dia pernah memakai mobil itu, jadi masih ingat mobilnya sampai sekarang.

Nora : "Kami saling memberi dan menerima"

Kelana : "Bahagia sekali bisa punya teman seperti itu"(42)

$>$ Konteks : Pembicaraan antara Kelana dan Nora, Nora adalah notaris yang mengurusi harta warisan yang ditinggalkan oleh Om Jo (Om Kelana). Percakapan terjadi di dalam mobil Nora, suasana pada saat itu sedih.

$>$ Maksud dari percakapan tersebut adalah, Nora merasa sangat kehilangan seorang teman yang perhatian seperti Om Jo dan teman yang seperti itu pula yang diinginkan oleh Kelana karena selama ini dia tidak mempunyai satu pun teman akrab.

Nora : "Kau lucu juga"
Kelana : "Aku nggak
bermaksud"(56)

$>$ Konteks : Pembicaraan antara Kelana dan Nora, Nora adalah notaris yang mengurusi harta warisan yang ditinggalkan oleh Om Jo (Om Kelana). Percakapan terjadi di dalam mobil Nora, suasana pada saat itu ceria

Maksud dari percakapan tersebut adalah, ternyata Kelana anak yang bisa bercanda, sebelumnya Nora menilai Dia adalah anak yang serius dan sulit 
untuk diajak bercanda. Namun, Kelana menutupi kejadian itu dengan purapura tidak bermaksud untuk bercanda.

Nora : "Bagaimana, ke?"

Kelana : "Persis seperti mimpiku, tante. Om jo duduk di situ"

Nora : "Luar biasa!"”(60)

Konteks : Pembicaraan antara Kelana dan Nora, Nora adalah notaris yang mengurusi harta warisan yang ditinggalkan oleh Om Jo (Om Kelana). Percakapan terjadi di pondok warisan Om Jo, suasana pada saat itu serius.

> Maksud dari percakapan tersebut adalah, apa yang dilihat Kelana di pondok dan kebun warisan sama seperti dimimpinya, karena sebelum mengetahui kabar meninggalnya Om Jo, Kelana beberapa kali bermimpi Om Jo duduk termenung sendirian di atap rumah yang dikelilingi dengan pohon buah-buahan yang lebat dan hal itu tidak disangka sebelumnya oleh Nora.

Nora : "Ke! Ada apa?"

Kelana : "Sudah tante. Nggak apaapa"

Nora : "Kau... kau... melihat sesuatu?"

Kelana : "Nggak, Tante. Aku membayangkan kejadian yang menimpa Oom Jo" (61)

$>$ Konteks : Pembicaraan antara Kelana dan Nora, Nora adalah notaris yang mengurusi harta warisan yang ditinggalkan oleh Om Jo (Om Kelana). Percakapan terjadi di pondok warisan Om Jo, suasana pada saat itu sedikit tegang.

Maksud dari percakapan tersebut adalah Nora menanyakan keadaan Kelana, karena pada saat itu Dia hampir jatuh setelah melihat ke atas atap. Dia membayangkan kejadian saat Om nya jatuh dari atap pondok tersebut dan meninggal dunia.

\section{Pembahasan}

Pada bagian ini akan dipaparkan klasifikasi data dan analisis tentang prinsip kerja sama dalam implikatur percakapan dalam novel Pelukan yang Dingin karya V. Lestari. Pada penelitian sebelumnya implikatur pragmatik sudah pernah diteliti oleh diteliti oleh Sulistyaningtyas (2009) dan Zakiyah (2015). Sulistyaningtyas dengan judul "Bahasa Indonesia dalam Wacana Propaganda Politik Kampanye Pemilu 2009 Satu Kajian Sosiopragmatik" mengungkap fungsi bahasa dalam politik, variasi bahasa dalam kampanye, dan tindak tutur pengungkap imlplikatur. Selanjutnya, Zakiyah dengan judul "Implikatur dalam Wacana Kampanye Politik Pilkada Calon Gubernur dan Calon Wakil Gubernur Provinsi Lampung Periode 2014-2019" mengungkap tindak tutur dan implikatur yang dominan dalam kampanye politik. Kedua penelitian tersebut lebih menekankan pada tindak tutur pengungkap implikatur. Berbeda dengan kedua penelitian tersebut, penelitian ini mengkhususkan pada percakapan novel untuk mengungkap imlikatur dan pelanggaran prinsip kerja sama yang ada dalam percakapan novel.

Data yang akan dianalisis di sini adalah berupa sampel yang berjumlah 77 percakapan, jumlah tersebut diambil dari 490 halaman dalam novel. Prinsip kerja sama yang akan digunanakan oleh peneliti yaitu teori Grice (dalam Wijana, 1996: 46) yang mengemukakan "bahwa di dalam rangka melaksanakan prinsip kerja sama itu, setiap penutur harus mematuhi 4 maksim percakapan, yakni maksim kuantitas (maxim of quantity), maksim kualitas (maxim of quality), maksim relevansi (maxim of relevance), maksim pelaksanaan (maxim of manner)". Jadi dari data yang ditemukan tersebut akan dianalisis berdasarkan pelanggaran dan kepatuhan maksim dalam data percakapan. Berikut ini hasil analisis pelanggaran dan kepatuhan prinsip kerja sama. 
Tabel 1 Analisis Pelanggaran dan Kepatuhan Prinsip Kerja Sama

\begin{tabular}{|c|c|c|c|}
\hline \multirow{2}{*}{ No } & \multirow{2}{*}{ Korpus Data } & \multicolumn{2}{|c|}{ Prinsip Kerja Sama } \\
\hline & & Melanggar Maksim & Mematuhi Maksim \\
\hline 1 & $\begin{aligned} \text { Singgih } & : \text { "Apa? Bicara..." } \\
\text { Kelana } & : \text { "Bapak nggak kasihan?" (16) }\end{aligned}$ & $\begin{array}{l}\text { - Kuantitas } \\
\text { - Pelaksanaan/ Cara }\end{array}$ & $\begin{array}{l}\text { - Kualitas } \\
\text { - Relevansi }\end{array}$ \\
\hline 2 & $\begin{array}{l}\text { Amelia : "Waduh, aku repot donk. Pekerjaanku } \\
\text { seabrek." } \\
\text { Kelana : “Ah, kita kan sudah santai sekarang. } \\
\text { Segalanya sudah diurus mesin ATM,” (17) }\end{array}$ & $\begin{array}{l}\text { - Kuantitas } \\
\text { - Pelaksanaan/ Cara }\end{array}$ & $\begin{array}{l}\text { - Kualitas } \\
\text { - Relevansi }\end{array}$ \\
\hline 3 & $\begin{array}{l}\text { Kelana : "Aku nggak suka baca koran" } \\
\text { Nora : "Nggak ada teman yang } \\
\text { memberitahumu?"(22) }\end{array}$ & - Pelaksanaan/ Cara & $\begin{array}{l}\text { - Kualitas } \\
\text { - Kuantitas } \\
\text { - Relevansi }\end{array}$ \\
\hline 4 & $\begin{array}{l}\text { Kelana : "Oh, mobilnya" } \\
\text { Nora } \\
\text { Kelana : Ya. Chevrolet pick-up warna hitam" }\end{array}$ & - Kuantitas & $\begin{array}{l}\text { - Kualitas } \\
\text { - Relevansi } \\
\text { - Pelaksanaan/ Cara }\end{array}$ \\
\hline 5 & $\begin{array}{l}\text { Nora } \quad: \text { "Kami saling memberi dan menerima" } \\
\text { Kelana } \\
\text { itu" (42) }\end{array}$ & - Pelaksanaan/ Cara & $\begin{array}{l}\text { - Kuantitas } \\
\text { - Kualitas } \\
\text { - Relevansi }\end{array}$ \\
\hline 6 & $\begin{array}{l}\text { Nora } \\
\text { Kelana } \\
\text { lain" (43) }\end{array}$ & $\begin{array}{l}\text { - Kuantitas } \\
\text { - Relevansi } \\
\text { - Pelaksanaan/ Cara }\end{array}$ & - Kualitas \\
\hline 7 & $\begin{array}{l}\text { : “Kau lucu juga” } \\
\text { : “Aku nggak bermaksud” (56) }\end{array}$ & $\begin{array}{l}\text { - Kualitas } \\
\text { - Relevansi } \\
\text { - Pelaksanaan/ Cara }\end{array}$ & - Kuantitas \\
\hline 8 & $\begin{array}{ll}\text { Nora } & \text { : "Bagaimana, ke?" } \\
\text { Kelana } & \text { : "Persis seperti mimpiku, tante. Om jo duduk } \\
\text { di situ" } & \\
\text { Nora } & : \text { : Luar biasa!"( (60) }\end{array}$ & - Kuantitas & $\begin{array}{l}\text { - Kualitas } \\
\text { - Relevansi } \\
\text { - Pelaksanaan/ Cara }\end{array}$ \\
\hline 9 & 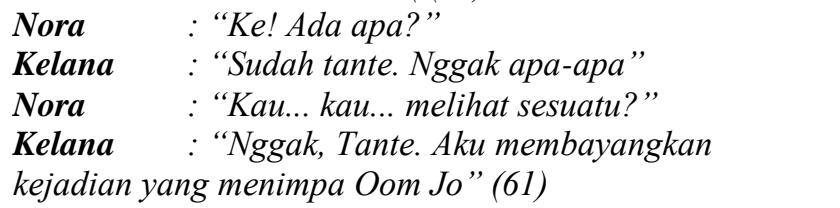 & $\begin{array}{l}\text { - Kualitas } \\
\text { - Relevansi } \\
\text { - Pelaksanaan/ Cara }\end{array}$ & - Kuantitas \\
\hline 10 & $\begin{array}{l}\text { Kelana : "Kalau mereka yang pengalaman saja } \\
\text { nggak bisa, apalagi aku, Tante" } \\
\text { Nora : "Siapa tahu tanganmu dingin" (68) }\end{array}$ & $\begin{array}{l}\text { - Kualitas } \\
\text { - Relevansi } \\
\text { - Pelaksanaan/ Cara }\end{array}$ & - Kuantitas \\
\hline 11 & $\begin{array}{l}\text { Kelana :" Jualnya ke mana, Tante?" } \\
\text { Nora } \quad: \text { "Tengkulak akan datang sendiri begitu } \\
\text { dikabari. Jual sendiri lebih repot. Harus buka kios di } \\
\text { pasar" (69) }\end{array}$ & - Kuantitas & $\begin{array}{l}\text { - Kualitas } \\
\text { - Relevansi } \\
\text { - Pelaksanaan/ Cara }\end{array}$ \\
\hline 12 & $\begin{array}{l}\text { Kelana : "Ponsel sih bawa, tapi charger nggak. } \\
\text { Memangnya mengapa, Tante?" } \\
\text { Nora : "Siapa tahu ingin menginap” (70) }\end{array}$ & - Relevansi & $\begin{array}{l}\text { - Kuantitas } \\
\text { - Kualitas } \\
\text { - Pelaksanaan/ Cara }\end{array}$ \\
\hline 13 & $\begin{array}{l}\text { Kelana : "Pulangnya aku yang menyetir ya, Tante. } \\
\text { Kelihatannya tante capek" } \\
\text { Nora : "Pulangnya mampir beli asinan dulu ya, } \\
\text { Ke" } \\
\text { Kelana : "Beres."(79) }\end{array}$ & - & $\begin{array}{l}\text { - Kuantitas } \\
\text { - Kualitas } \\
\text { - Relevansi } \\
\text { - Pelakasanaan/ Cara }\end{array}$ \\
\hline 14 & $\begin{array}{l}\text { : “Aku akan mengelolanya, Tante” } \\
\text { : "Bagus. Itu juga hasil perenunganmu?" } \\
\text { : "Mungkin.”(84) }\end{array}$ & $\begin{array}{ll}\text { - } & \text { Kualitas } \\
\text { - } & \text { Relevansi } \\
\text { - } & \text { Pelaksaana/ Cara }\end{array}$ & - Kuantitas \\
\hline 15 & : “Ah, jangan menyanjung dulu, Tante. Aku & - Kuantitas & - Kualitas \\
\hline
\end{tabular}




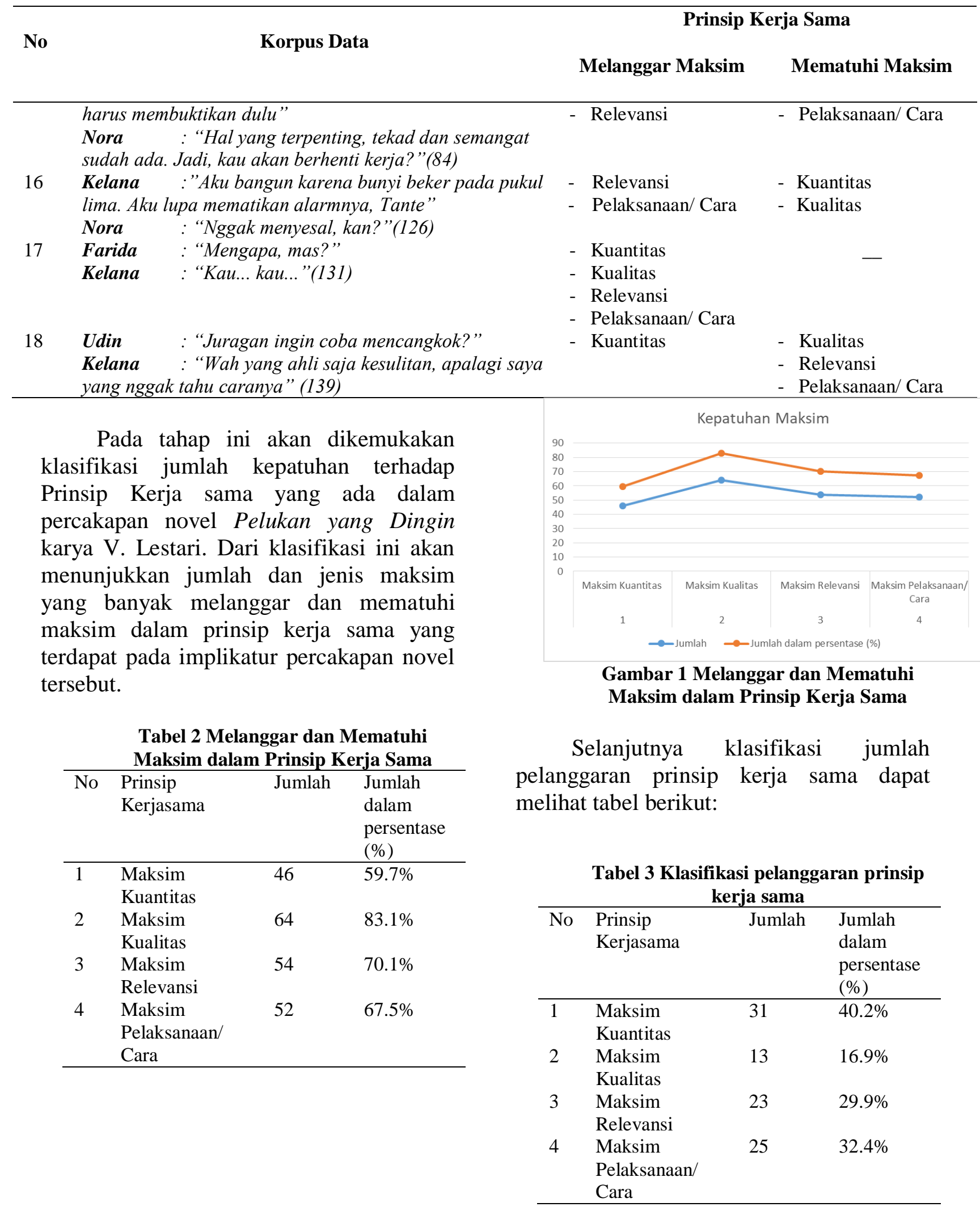




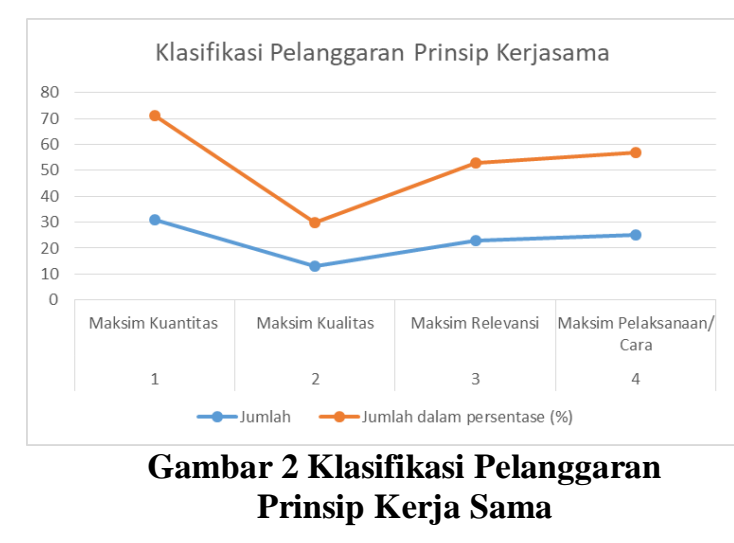

Dari tabel 3 dapat dideskripsikan bahwa penggunaan maksim prinsip kerja sama yang terdapat pada percakapan novel Pelukan yang Dingin karya V. Lestari. Novel ini lebih banyak mematuhi atau menggunakan maksim kualitas dibandingkan maksim kuantitas, maksim relevansi, maksim pelaksanaan/ cara. Percakapan yang terdapat dalam novel ini masih termasuk patuh atau menggunakan prinsip kerja sama dengan lumayan tepat karena setelah dianalisis dan diprosentasekan angka menunjukkan $59.7 \%$ ke atas. Sementara itu, yang melanggar atau tidak menggunakan prinsip kerja sama adalah $40.2 \%$ ke bawah.

\section{SIMPULAN}

Berdasarkan hasil penelitian dan pembahasan tentang Implikatur percakapan dalam novel Pelukan yang Dingin karya V. Lestari, dapat disimpulkan sebagai berikut.

Pertama, implikatur percakapan yang ditemukan yaitu, Pembicara berharap bahwa lawan bicaranya dapat memahami apa yang dia katakan, apa yang dia katakan sesuai dengan acara, pembicara berpurapura tidak mengerti tuturannya, dan pembicara tidak mengerti apa yang dia katakan, pembicara membutuhkan kepercayaan dari mitra tutur, pembicara kurang memahami maksud dari mitra tutur, pembicara menginginkan pemahaman tentang maksud mitra tutur, dan pembicara harus mengambil tindakan yang diminta oleh mitra tutur.

Kedua, penyimpangan terhadap prinsip kerja sama yang paling banyak ditemukan adalah penyimpangan terhadap maksim kuantitas, karena percakapan yang dianalisis kebanyakan tidak memberikan informasi yang tidak sesuai dengan fakta, serta tidak dapat dipertanggungjawabkan jadi melanggar maksim kuantitas. Sementara itu, kepatuhan terhadap prinsip kerja sama yang paling banyak ditemukan adalah maksim kualitas karena percakapan yang dianalisis banyak yang dapat memberikan pesan atau informasi yang sungguh-sungguh memadai, dirasa cukup, dan dipandang seinformatif mungkin kepada mitra tutur.

\section{REFERENSI}

Tim Penyusun. (2016). Kamus Besar Bahasa Indonesia (KBBI). [Online] Tersedia pada laman http://kbbi.web.id/pusat, (diakses 22 November 2019).

http://www.bimbie.com/implikatur.htm, (diakses pada 25 November 2019).

http://www.scribd.com/doc/87465519/22/ metode-dan-teknikpenyajian-hasilanalisis (diakses pada 25 November 2019).

Lestari. V. (2010). Pelukan yang Dingin. Jakarta: PT Gramedia Pustaka Umum.

Rahardi, R. Kunjana. (2005). Pragmatik: kesantunan imperatif Bahasa Indonesia. Jakarta: Erlangga.

Sumarsono. (2010). Pragmatik. Singaraja: Universitas Pendidikan Ganesa

Suyono. (1990). Pragmatik Dasar-Dasar dan Pengajaran. Malang: Yayasan Asih Asah Malang.

Sudaryanto. (2015). Metode dan Aneka Teknik Analisis Bahasa, hlm. 6, 15, 203, 241. Yogyakarta: Sanata Dharma University Press.

Sugiyono. (2014). Memahami Penelitian Kualitatif. Bandung: Alfabeta.

Sulistyaningtyas, T. (2009). "Bahasa Indonesia dalam Wacana Propaganda Politik Kampanye Pemilu 2009 Satu Kajian Sosiopragmatik". Sosioteknologi, Vol. 8, No. 17, Agustus 2009. hlm. 637-645. 
http://journals.itb.ac.id/index.php/sostek /article/view/1026.

Wijana, D.P. dan Rochmadi. (2009). Analisis Wacana Pragmatik: Kajian Teori dan Analisis, hlm. 4. Surakarta: Yuma Pustaka.

Wijana, I Dewa Putu. (1996). Dasar-dasar pragmatik, Yogyakarta: Andi Offset

Zakiyah, N. (2015). "Implikatur dalam Wacana Kampanye Politik Pilkada Calon Gubernur dan Calon Wakil Gubernur Provinsi Lampung Periode 2014-2019 (Tinjauan Pragmatik)". TAPIS. Vol. 11. No. 1. Januari-Juni $2015 . \quad$ hlm. 20-33. http://ejournal.radenintan.ac.id/index.ph p/TAPIs/article/view/839. 